1 Differential vaginal Lactobacillus species metabolism of glucose, $\mathrm{L}$ and $\mathrm{D}$-lactate by ${ }^{13} \mathrm{C}$-nuclear magnetic

2

3

4

5

6

\section{resonance spectroscopy}

Emmanuel Amabebe ${ }^{a}$, e.amabebe@sheffield.ac.uk

Dilly O. Anumba ${ }^{a}$, d.o.c.anumba@sheffield.ac.uk

Steven Reynolds ${ }^{\mathrm{b} *}$, steven.reynolds@ sheffield.ac.uk

aDepartment of Oncology and Metabolism, University of Sheffield, Level 4, Jessop Wing, Tree Root Walk, Sheffield S10 2SF, UK.

bDepartment of Infection, Immunity and Cardiovascular Disease, University of Sheffield, Royal Hallamshire hospital, Glossop Road, Sheffield S10 2JF, UK

\section{*Corresponding author}

Dr Steven Reynolds, BSc (Hons), PhD

Academic Unit of Radiology, Department of Infection, Immunity and Cardiovascular Disease, University of Sheffield, Royal Hallamshire hospital, Glossop Road, Sheffield S10 2JF, UK. +44 1142159596 , steven.reynolds@sheffield.ac.uk

\section{Acknowledgements:}

We are grateful to the University of Sheffield, UK, for providing support and the 9.4T MRS spectrometer with which this study was performed. 


\section{Abstract}

\section{Introduction}

30 Cervicovaginal dysbiosis can lead to infection-associated spontaneous preterm birth.

\section{Objective}

32 To determine whether vaginal Lactobacillus species, L. crispatus and L. jensenii, differentially metabolise glucose, L- and/or D-lactate to propagate their survival/dominance.

\section{Methods}

35 Bacteria were incubated anaerobically for $24 \mathrm{~h}$ at $37{ }^{\circ} \mathrm{C}$, with ${ }^{13} \mathrm{C}_{\mathrm{u}}$-glucose, ${ }^{13} \mathrm{C}_{3}$-D-lactate or ${ }^{13} \mathrm{C}_{3}$ - $\mathrm{L}$-lactate 36 (singularly or combined) for $24 \mathrm{~h} .{ }^{13} \mathrm{C}$-spectra were acquired using a $9.4 \mathrm{~T}$ NMR spectrometer.

\section{$37 \quad$ Results}

L. crispatus and L. jensenii ( $\mathrm{n}=6$ each) metabolised ${ }^{13} \mathrm{C}$-glucose to ${ }^{13} \mathrm{C}$-lactate and ${ }^{13} \mathrm{C}$-acetate. L. jensenii converted more ${ }^{13} \mathrm{C}_{3}$-D- or ${ }^{13} \mathrm{C}_{3}$-L-lactate to ${ }^{13} \mathrm{C}$-acetate than L. crispatus, $\mathrm{p}<0.001$.

\section{Conclusion}

41 Conversion of glucose and lactate to acetate by L. jensenii compared to L. crispatus, suggests a possibly important

42 pathomechanism of dysbiosis and infection-associated spontaneous preterm birth.

Keywords: Preterm birth, vaginal lactobacilli, lactate, acetate, ${ }^{13} \mathrm{C}-\mathrm{NMR}$. 


\section{Introduction}

In conjunction with the host vaginal habitat, the vaginal bacteria produce unique metabolic by-products. In a healthy vagina, lactobacilli are the predominant species and have been linked to increased likelihood of term delivery (Amabebe and Anumba, 2018; Stafford et al., 2017). The four major vaginal lactobacilli (L. crispatus, L. jensenii, L. iners and L. gasseri) differentially produce L- and D-lactic acid that lowers the $\mathrm{pH}$ of the cervicovaginal space, creating unfavourable conditions for other invading species. D-lactic acid is believed to be more potent than L-lactic acid in relation to protection against colonisation by potentially pathogenic organisms within the vagina and the accompanying inflammatory response (Witkin et al., 2013). Anaerobes are also endogenous to the vagina and are associated with infection and preterm birth (PTB, i.e. delivery $<37$ weeks of gestation) especially when lactobacilli are deficient (Amabebe and Anumba, 2018).

Metabolism by cells can be tracked by ${ }^{13} \mathrm{C}-$ Nuclear Magnetic Resonance (NMR) to examine specific pathways (Buescher et al., 2015). The use of ${ }^{13} \mathrm{C}$ labelled substrates means that they are metabolised identically to those found naturally, with the cell viability maintained throughout the experiment. Additionally, strategic placement of the ${ }^{13} \mathrm{C}$ label (Buescher et al., 2015) allows the activity of single or multiple metabolic pathways to be identified, even if the end product is the same (Bruntz et al., 2017).

Although, lactobacilli are known to thrive in the acidic condition of the vagina $(\mathrm{pH}<4.5)$, the mechanism underpinning how lactobacilli, and other anaerobes, interact with lactic acid remains unresolved (Amabebe and Anumba, 2018). In this short communication, we report on the use of ${ }^{13} \mathrm{C}-\mathrm{NMR}$ to examine how different Lactobacillus species (L. crispatus and L. jensenii) differentially metabolise glucose, L- and/or D-lactate to propagate their survival and dominance.

\section{Material and Methods}

\section{Bacterial culture}

One strain each of two common vaginal Lactobacillus species L. crispatus (ATCC 33820) and L. jensenii (ATCC 25258) were cultured in De Man, Rogosa and Sharpe broth (MRS, Oxoid CM0359, Thermo Scientific, Bassingstoke, UK), under anaerobic $\left(80 \% \mathrm{~N}_{2}, 10 \% \mathrm{CO}_{2}, 10 \% \mathrm{H}_{2}\right)$ condition at $37^{\circ} \mathrm{C}$ for $24 \mathrm{~h}$. After this time, 50 $\mu \mathrm{l}$ of bacteria in broth was transferred to $400 \mu \mathrm{l}$ of fresh broth and then subcultured with the addition of $50 \mu 1100$ $\mathrm{mM}{ }^{13} \mathrm{C}_{\mathrm{u}}$-glucose, ${ }^{13} \mathrm{C}_{3}$-D-lactate, ${ }^{13} \mathrm{C}_{3}$-L-lactate (or $25 \mu \mathrm{l}$ each when ${ }^{13} \mathrm{C}_{\mathrm{u}}$-glucose and ${ }^{13} \mathrm{C}_{3}$-D/L-lactate were combined) for a further 24 hours (all sourced from Sigma Aldrich, Gillingham, UK). Six separate incubation were performed for each species. Post incubation, samples were stored at $-80{ }^{\circ} \mathrm{C}$ until ${ }^{13} \mathrm{C}-\mathrm{NMR}$ scanning. Broth only 
(non-inoculated medium) and bacterial samples without ${ }^{13} \mathrm{C}$-labelled substrates were used as controls. The amount of bacterial colony forming units $(\mathrm{CFU}) / \mu \mathrm{l}$ were estimated at time of ${ }^{13} \mathrm{C}$-substrate addition using a Helber counting chamber with Thoma ruling (area $=1 / 400 \mathrm{~mm}^{2}$, depth $=0.02 \mathrm{~mm}$; Hawksley Z30000).

\section{NMR acquisition and processing}

${ }^{13} \mathrm{C}-\mathrm{NMR}$ samples were prepared containing $430 \mu \mathrm{l}$ bacterial sample in a $5 \mathrm{~mm}$ NMR tube (Norell, Morganton, NC, USA) with $20 \mu \mathrm{l} \mathrm{D}_{2} \mathrm{O}$ (Sigma Aldrich) and $10 \mu \mathrm{l}$ of $200 \mathrm{mM}{ }^{13} \mathrm{C}$-urea (chemical shift and concentration reference, Sigma Aldrich) and $15 \mu$ l of penicillin/streptomycin (tube concentration $~ 105$ units/ml penicillin and $\sim 105 \mu \mathrm{g} / \mathrm{ml}$ streptomycin, Sigma Aldrich).

Spectra were acquired by a 9.4T Bruker AVANCE III NMR spectrometer (Bruker BioSpin GmbH, Karlsruhe, Germany) using a ${ }^{13} \mathrm{C}\left\{{ }^{1} \mathrm{H}\right\}$ inverse-gated pulse sequence (Spectral Width $=239 \mathrm{ppm}$, Number of acquisitions $=$ 4096, Acquisition Time $=0.5 \mathrm{~s}$, Delay Time $=2 \mathrm{~s}$, Time domain points $=24036$, flip angle $=16^{\circ}$ ) at room temperature $\left(21^{\circ} \mathrm{C}\right)$. Each acquired spectrum was apodised with a $5 \mathrm{~Hz}$ exponential line broadening function, phase and baseline corrected using Bruker Topspin v3.4 software and referenced to the urea signal at a frequency offset $\delta=165.5 \mathrm{ppm}$.

\section{Metabolite integration and normalisation}

Spectrum integrals were determined using a custom peak fitting algorithm (Matlab R2018b, Mathworks, Natick, MA, USA) to identify and separate overlapping peaks where singlet and doublet peaks were present at a particular chemical shift (Fig. 1a: ${ }^{13} \mathrm{C}_{3}$-lactate, $22.1-23.05$ ppm; ${ }^{13} \mathrm{C}_{3}$-acetate, $23.2-26.5$ ppm). Doublet peaks were summed to give an integral for lactate or acetate formed from ${ }^{13} \mathrm{C}_{\mathrm{u}}$-glucose metabolism (Fig. 1b).

Metabolite integrals were normalised by the concentration of live bacteria present in the incubated samples. This was estimated by measuring the lactate integral, $\mathrm{Lac}_{\mathrm{Broth}}$, from the conversion of broth glucose (i.e. not ${ }^{13} \mathrm{C}-\mathrm{labelled}$ ) after 48 hours of incubation ( $24 \mathrm{~h}$ prior to ${ }^{13} \mathrm{C}$-substrate addition plus a further $24 \mathrm{~h}$ incubation post ${ }^{13} \mathrm{C}$ addition) and was not observed in broth only samples. For each incubation experiment all integrals were divided by Lac $\mathrm{Broth}_{\mathrm{B}}$

\section{Statistical analysis}

Statistical analysis was also performed using Matlab with D'Agostino-Pearson's tests for normality of data and a Kruskal-Wallis with Bonferroni post-hoc test (KW-B) for comparison of multiple groups with $\mathrm{p}<0.05$ taken as significant. Comparison between lactobacilli acetate and lactate integrals were performed using either Student's t-test or Wilcoxon rank-sum test depending on the outcome of the normality test. 


\section{Results and Discussion}

112 The average count (CFU) of each bacterial species before incubation with ${ }^{13} \mathrm{C}$-labelled substrates was: $L$. crispatus $=4.4 \times 10^{7} \pm 7.0 \times 10^{6} \mathrm{CFU} / \mu \mathrm{l}$; and L. jensenii $=7.3 \times 10^{7} \pm 1.1 \times 10^{7} \mathrm{CFU} / \mu \mathrm{l}(\mathrm{p}=0.1)$. The ${ }^{13} \mathrm{C}$-spectra showed conversion of glucose (natural abundance and ${ }^{13} \mathrm{C}$-labelled) to lactate $(22.8 \mathrm{ppm})$ and acetate $(23.8 \mathrm{ppm})$ for both species ( $n=6$ per species, Fig. 1). Higher quantities of lactate were produced by L. jensenii than L. crispatus for all ${ }^{13} \mathrm{C}_{\mathrm{u}}$-glucose containing incubations although these were not significant (Fig. 2a). The addition of ${ }^{13} \mathrm{C}_{3}-\mathrm{L} / \mathrm{D}-$ lactate to the incubation suppressed the conversion of ${ }^{13} \mathrm{C}_{\mathrm{u}}$-glucose to lactate (Fig, 2a). L. jensenii showed significantly higher conversion of both enantiomers of ${ }^{13} \mathrm{C}_{3}$-lactate to acetate $(23.8 \mathrm{ppm})$ than L. crispatus (L. crispatus vs L. jensenii: D-lactate to acetate: $0.26 \pm 0.10$ vs $1.71 \pm 0.15, \mathrm{p}<0.001$; L-lactate to acetate: $0.11 \pm$ 0.04 vs $1.68 \pm 0.14, \mathrm{p}<0.001$, Fig. $2 \mathrm{~b})$. Six of the L. jensenii ${ }^{13} \mathrm{C}$ spectra $\left({ }^{13} \mathrm{C}\right.$-glucose, $\mathrm{n}=2 ;{ }^{13} \mathrm{C}$-glucose/Llactate, $\mathrm{n}=2 ;{ }^{13} \mathrm{C}$-glucose/D-lactate, $\mathrm{n}=1 ;{ }^{13} \mathrm{C}$-L-lactate, $\mathrm{n}=1$ ) also showed peaks at 32.4 and $180.6 \mathrm{ppm}$ (assigned as succinate from HMBC spectra, data not shown).

Results show that Lactobacillus species that are present in the vagina differentially metabolise ${ }^{13} \mathrm{C}$-labelled glucose and lactate to produce acetate and other metabolites. L. jensenii spectra showed that this species was able to convert more D- or L-lactate to acetate than L. crispatus. D-lactate is believed to be a more potent anti-infection and anti-inflammatory agent than L-lactate (van de Wijgert et al., 2014; Witkin and Linhares, 2017; Witkin et al., 2013) and other studies have shown that L. crispatus produces more D-lactate than L. jensenii (Amabebe and Anumba, 2018; van de Wijgert et al., 2014; Witkin and Linhares, 2017; Witkin et al., 2013). This study observed that L. jensenii converted a higher amount of ${ }^{13} \mathrm{C}_{\mathrm{u}}$-glucose to lactate than L. crispatus. We did not ascertain if the lactate produced was either the L- or D isomer. However, this could be done by either an NMR chiral shift reagent (Zhang et al., 2017a; Zhang et al., 2017b) or absolute quantification of these isomers by enzyme-based spectrophotometry as we have previously demonstrated (Amabebe et al., 2019; Amabebe et al., 2016a; Cavanagh et al., 2019).

Bacterial load (CFU) was not used for normalisation, as this did not correlate with ${ }^{13} \mathrm{C}$-lactate integrals observed in the spectra (data not shown). Hence, the integrals in this study were normalised based on the assumption that the observed lactate peak arising from non- ${ }^{13} \mathrm{C}$-labelled glucose present in the media (singlet peak between the doublet for lactate at $22.8 \mathrm{ppm}$, Fig 2a) was proportional to the concentration of live bacteria. Justification for this approach was made by the observation of significant correlations between the doublet peak ${ }^{13} \mathrm{C}$-lactate integrals, 
140 Using this approach could potentially underestimate the quantity of live bacteria due to further metabolism of

141 lactate, e.g. to acetate. Considering acetate concentration is confounded by its presence in the broth, which then

142 overestimates the bacteria concentration (acetate integrals from broth only spectra would need to be measured to

143 account for this). Using CFU for normalisation requires careful assessment of the inhomogeneity in bacteria

144 distribution that can make this method inaccurate. Additionally, the viability of bacteria would need to be

145 determined, as some of the bacteria will be dead. Furthermore, bacteria that were metabolically active at the start

146 of the incubation would die over the duration of the incubation leading to an over correction of the integrals.

147 The conversion of glucose and lactate to acetate and succinate by L. jensenii compared to L. crispatus, suggests that this may be an important pathomechanism of dysbiosis, altered vaginal $\mathrm{pH}$, infection and infection-associated spontaneous preterm birth. Elevated amounts of acetate and succinate in the vaginal space is associated with increased $\mathrm{pH}$ and risk of infection such as bacterial vaginosis (Aldunate et al., 2015; Ceccarani et al., 2019), a known risk factor of preterm birth and other poor reproductive outcomes (Amabebe and Anumba, 2018). Vaginal bacterial communities dominated by $L$. jensenii usually have higher $\mathrm{pH}$ compared to when L. crispatus predominates (Aldunate et al., 2015). We have previously observed that symptomatic women at risk of preterm birth show elevated cervicovaginal fluid acetate (Amabebe et al., 2016a; Amabebe et al., 2016b), which can be combined with pro-inflammatory mediators to improve its performance as a predictive marker (Amabebe et al., 2019).

These experiments were performed on bacteria that had been freeze thawed. As NMR is a non-destructive technique, it would be possible to apply this method to live bacteria to sequentially acquire spectra and determine the rate of conversion of substrates. Whilst it would be important to characterise the most common vaginal strains of these species, alternative strains could also be characterised. Future studies will be expanded to other Lactobacillus species and strains such as L. iners and L. gasseri and anaerobes including Gardnerella, Bacteroides and Mobiluncus, as well as fungi (e.g. Candida albicans) that are known to exist within the vaginal milieu.

\section{Declarations}

\section{Funding:}

This research did not receive any specific grant from funding agencies in the public, commercial, or not-for-profit sectors. However, EA and DA are funded by National Institute for Health Research (NIHR, 17/63/26).

\section{Conflict of interest statement:}

168 The authors have no conflicts of interest to declare. 
bioRxiv preprint doi: https://doi.org/10.1101/2020.03.10.985580; this version posted March 11, 2020. The copyright holder for this preprint (which was not certified by peer review) is the author/funder. All rights reserved. No reuse allowed without permission.

This work was conceived and conceptualised by EA and SR. EA and SR acquired and analysed the data with DA supervising. All authors contributed to drafting and review of the manuscript, and approved the final version for submission.

\section{References:}

Aldunate, M., Srbinovski, D., Hearps, A.C., Latham, C.F., Ramsland, P.A., Gugasyan, R., Cone, R.A. and Tachedjian, G. (2015) Antimicrobial and immune modulatory effects of lactic acid and short chain fatty acids produced by vaginal microbiota associated with eubiosis and bacterial vaginosis. Frontiers in Physiology 6.

Amabebe, E. and Anumba, D.O.C. (2018) The Vaginal Microenvironment: The Physiologic Role of Lactobacilli. 5.

Amabebe, E., Reynolds, S., He, X., Wood, R., Stern, V. and Anumba, D.O.C. (2019) Infection/inflammationassociated preterm delivery within 14 days of presentation with symptoms of preterm labour: A multivariate predictive model. PLOS ONE 14, e0222455.

Amabebe, E., Reynolds, S., Stern, V., Stafford, G., Paley, M. and Anumba, D.O. (2016a) Cervicovaginal Fluid Acetate: A Metabolite Marker of Preterm Birth in Symptomatic Pregnant Women. Front Med (Lausanne) 3, 48.

Amabebe, E., Reynolds, S., Stern, V.L., Parker, J.L., Stafford, G.P., Paley, M.N. and Anumba, D.O. (2016b) Identifying metabolite markers for preterm birth in cervicovaginal fluid by magnetic resonance spectroscopy. Metabolomics 12, 67.

Bruntz, R.C., Lane, A.N., Higashi, R.M. and Fan, T.W. (2017) Exploring cancer metabolism using stable isotoperesolved metabolomics (SIRM). J Biol Chem 292, 11601-11609.

Buescher, J.M., Antoniewicz, M.R., Boros, L.G., Burgess, S.C., Brunengraber, H., Clish, C.B., DeBerardinis, R.J., Feron, O., Frezza, C., Ghesquiere, B., Gottlieb, E., Hiller, K., Jones, R.G., Kamphorst, J.J., Kibbey, R.G., Kimmelman, A.C., Locasale, J.W., Lunt, S.Y., Maddocks, O.D., Malloy, C., Metallo, C.M., Meuillet, E.J., Munger, J., Noh, K., Rabinowitz, J.D., Ralser, M., Sauer, U., Stephanopoulos, G., St-Pierre, J., Tennant, D.A., Wittmann, C., Vander Heiden, M.G., Vazquez, A., Vousden, K., Young, J.D., Zamboni, N. and Fendt, S.M. (2015) A roadmap for interpreting (13)C metabolite labeling patterns from cells. Curr Opin Biotechnol 34, 189-201.

Cavanagh, M., Amabebe, E. and Anumba, D.O.C. (2019) Differential Cytokine and Metabolite Production by Cervicovaginal Epithelial Cells Infected with Lactobacillus crispatus and Ureaplasma urealyticum. Anaerobe, 102101.

Ceccarani, C., Foschi, C., Parolin, C., D'Antuono, A., Gaspari, V., Consolandi, C., Laghi, L., Camboni, T., Vitali, B., Severgnini, M. and Marangoni, A. (2019) Diversity of vaginal microbiome and metabolome during genital infections. Scientific Reports 9, 14095.

Stafford, G.P., Parker, J.L., Amabebe, E., Kistler, J., Reynolds, S., Stern, V., Paley, M. and Anumba, D.O.C. (2017) Spontaneous Preterm Birth Is Associated with Differential Expression of Vaginal Metabolites by Lactobacilli-Dominated Microflora. Front Physiol 8, 615.

van de Wijgert, J.H.H.M., Borgdorff, H., Verhelst, R., Crucitti, T., Francis, S., Verstraelen, H. and Jespers, V. (2014) The Vaginal Microbiota: What Have We Learned after a Decade of Molecular Characterization? PLOS ONE 9, e105998. 
Witkin, S. and Linhares, I. (2017) Why do lactobacilli dominate the human vaginal microbiota? BJOG: An International Journal of Obstetrics \& Gynaecology 124, 606-611.

Witkin, S.S., Mendes-Soares, H., Linhares, I.M., Jayaram, A., Ledger, W.J. and Forney, L.J. (2013) Influence of vaginal bacteria and D- and L-lactic acid isomers on vaginal extracellular matrix metalloproteinase inducer: implications for protection against upper genital tract infections. mBio 4, e00460-13.

225

226

227

228

229

230

231

232

233

234

235

236

237

238

239

240

241

Zhang, L., Martins, A.F., Mai, Y., Zhao, P., Funk, A.M., Clavijo Jordan, M.V., Zhang, S., Chen, W., Wu, Y. and Sherry, A.D. (2017a) Imaging Extracellular Lactate In Vitro and In Vivo Using CEST MRI and a Paramagnetic Shift Reagent. Chemistry 23, 1752-1756.

Zhang, L., Martins, A.F., Zhao, P., Tieu, M., Esteban-Gomez, D., McCandless, G.T., Platas-Iglesias, C. and Sherry, A.D. (2017b) Enantiomeric Recognition of d- and 1-Lactate by CEST with the Aid of a Paramagnetic Shift Reagent. J Am Chem Soc 139, 17431-17437. 
a)
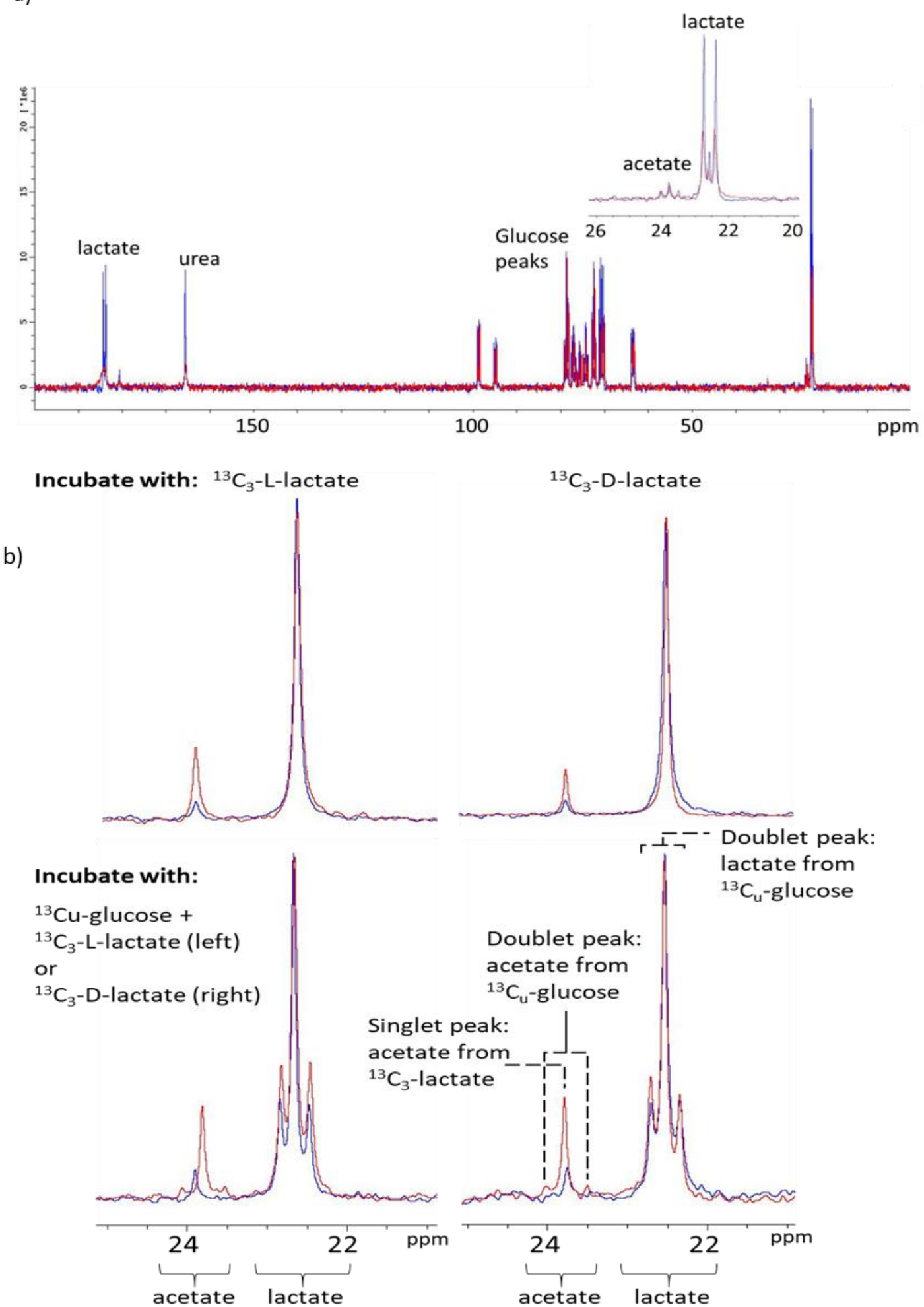

${ }^{13} \mathrm{C}_{\mathrm{u}}$-glucose

inglet peak: cetate from
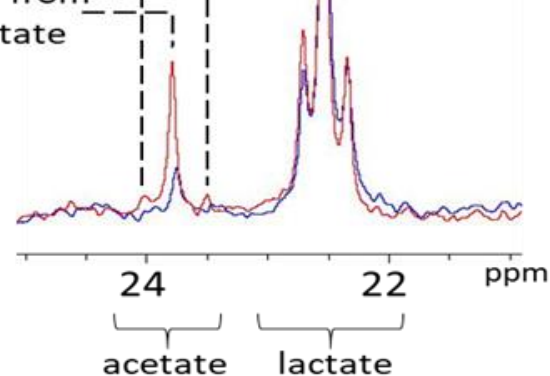

Figure 1: a) Overlaid ${ }^{13} \mathrm{C}-\mathrm{NMR}$ spectra of $L$. crispatus (blue) and $L$. jensenii (red) incubated with ${ }^{13} \mathrm{C}_{\mathrm{u}^{-}}$-glucose. Inset shows a zoomed region of the spectrum $20-26$ ppm. b) L. crispatus (blue) and L. jensenii (red) incubated with either: top, ${ }^{13} \mathrm{C}_{3}$-L-lactate (left) or ${ }^{13} \mathrm{C}_{3}$-D-lactate (right); bottom, ${ }^{13} \mathrm{C}_{\mathrm{u}}$-glucose $+{ }^{13} \mathrm{C}_{3}$-L-lactate (left) or ${ }^{13} \mathrm{C}_{\mathrm{u}^{-}}$ glucose $+{ }^{13} \mathrm{C}_{3}$-D-lactate (right). Spectra scaled to lactate peak height. Doublet peaks of lactate and acetate arise from the conversion of ${ }^{13} \mathrm{C}_{\mathrm{u}}$-glucose. Singlet peaks arise from either singly labelled ${ }^{13} \mathrm{C}_{3}$-D/L-lactate or substrates with natural abundance ${ }^{13} \mathrm{C}(1.1 \%)$. 


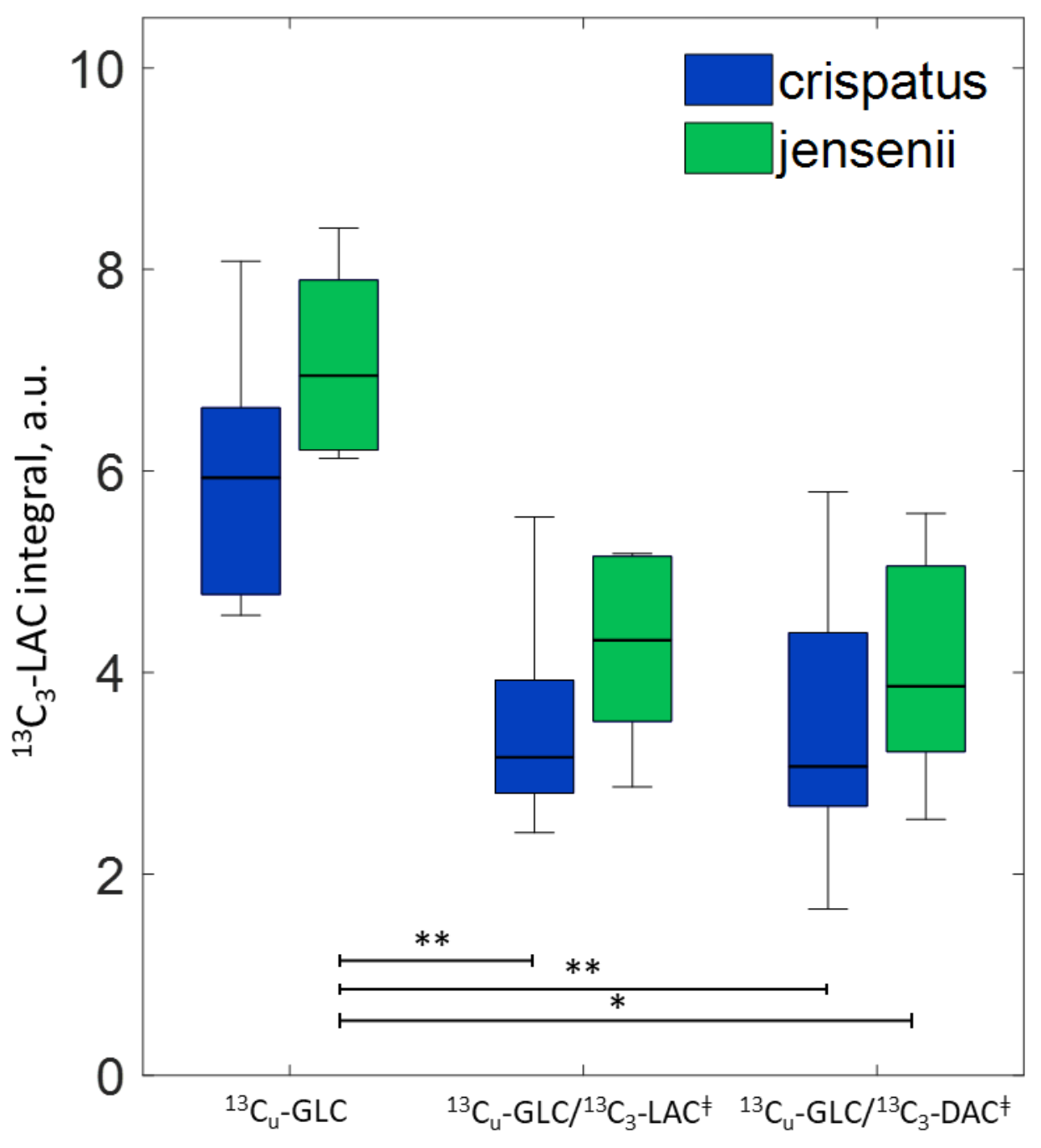




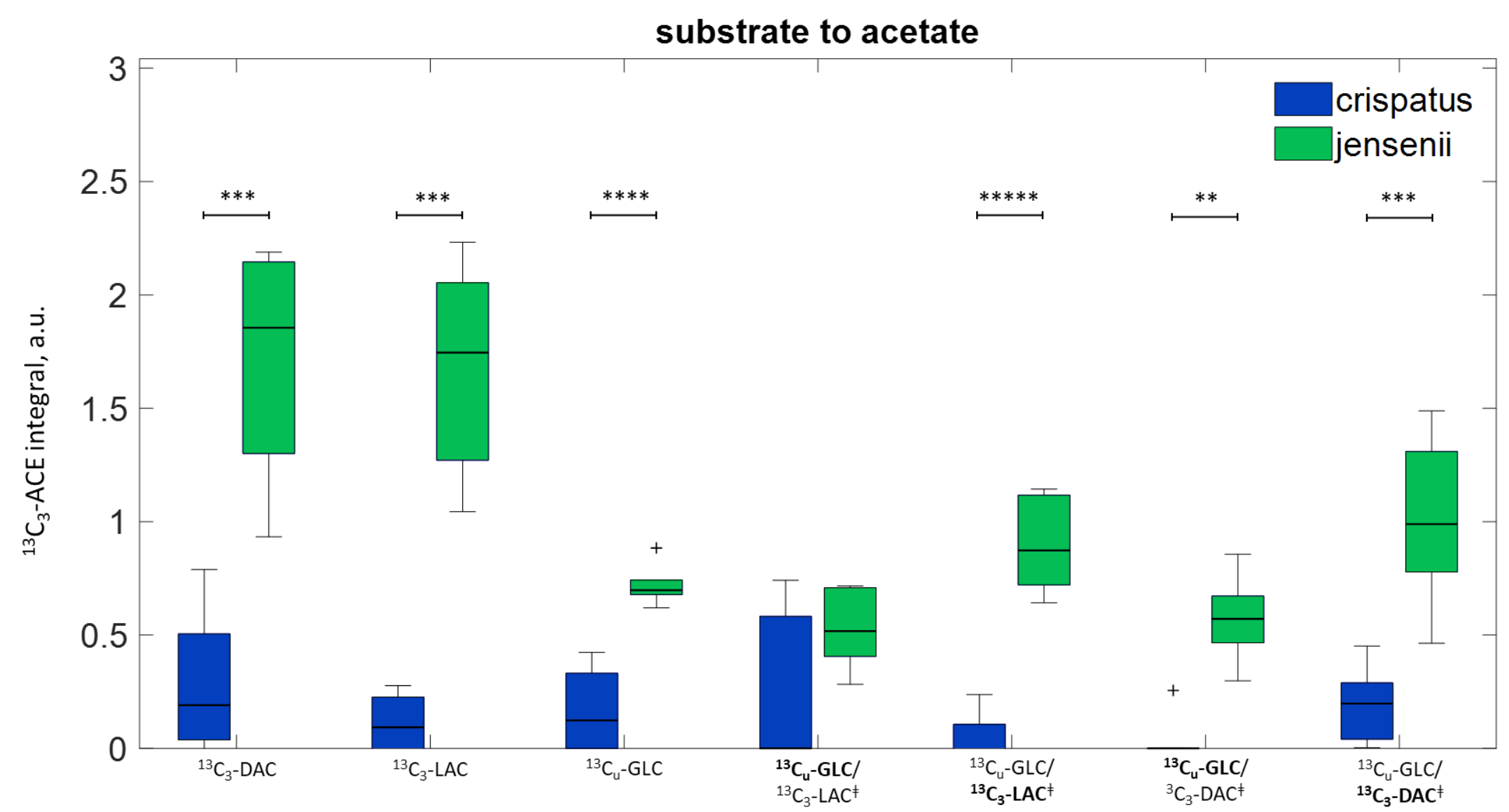

Figure 2: a) Normalised ${ }^{13} \mathrm{C}_{3}$-lactate integrals for the conversion of ${ }^{13} \mathrm{C}_{\mathrm{u}}$-glucose (GLC), ${ }^{13} \mathrm{C}_{\mathrm{u}}$-glucose $+{ }^{13} \mathrm{C}_{3}$-L-lactate (LAC) or ${ }^{13} \mathrm{C}_{\mathrm{u}}$-glucose $+{ }^{13} \mathrm{C}_{3}$-D-lactate (DAC). ${ }^{4}$ For combination incubations, the source substrate that is converted to lactate is ${ }^{13} \mathrm{C}_{\mathrm{u}}$-glucose (as detected from doublet peak in spectrum). Kruskal-Wallis with Bonferroni post-hoc test: ${ }^{*} \mathrm{p}<0.05$, ${ }^{* *} \mathrm{p}<0.01$. b) Normalised ${ }^{13} \mathrm{C}_{3}$-acetate (ACE) integrations for the conversion of ${ }^{13} \mathrm{C}_{\mathrm{u}}$-glucose $(\mathrm{GLC}),{ }^{13} \mathrm{C}_{\mathrm{u}}$-glucose $+{ }^{13} \mathrm{C}_{3}$-L-lactate $(\mathrm{LAC})$ or ${ }^{13} \mathrm{C}_{\mathrm{u}}$-glucose + ${ }^{13} \mathrm{C}_{3}$-D-lactate (DAC). $\neq$ For combination incubations, the source substrate that is converted to acetate is highlighted in bold. Boxplots show median, interquartile range (IQR) and whiskers (1.5xIQR). Wilcoxon rank sum: $* * \mathrm{p}<0.01, * * * \mathrm{p}<0.001, * * * * \mathrm{p}<0.0001, * * * * * \mathrm{p}<0.00001$ 
bioRxiv preprint doi: https://doi.org/10.1101/2020.03.10.985580; this version posted March 11, 2020. The copyright holder for this preprint (which was not certified by peer review) is the author/funder. All rights reserved. No reuse allowed without permission. 